\title{
The layering of a mountain podzol can strongly affect the distribution of infiltrated water in the soil profile
}

\author{
Lukáš Jačka $^{1 *}$, Jiří Pavlásek ${ }^{1}$, Jana Kalibová ${ }^{2}$ Petr Bašta ${ }^{1}$, Martin Kovář ${ }^{1}$, Václav Kuráž ${ }^{3}$ \\ ${ }^{1}$ Department of Water Resources and Environmental Modeling, Faculty of Environmental Sciences, Czech University of Life Sciences \\ Prague, Kamýcká 129, Praha 6 - Suchdol, 165 21, Czech Republic. \\ 2 Department of Land Use and Improvement, Faculty of Environmental Sciences, Czech University of Life Sciences Prague, Kamýcká 129 , \\ Praha 6 - Suchdol, 165 21, Czech Republic. \\ ${ }^{3}$ Department of Irrigation, Drainage and Landscape Engineering, Faculty of Civil Engineering, Czech Technical University in Prague, \\ Thákurova 7, Praha 6, 166 29, Czech Republic. \\ * Corresponding author. Tel.: +420 224383 827. Fax: +420 234381 854. E-mail: jacka@fzp.czu.cz
}

\begin{abstract}
The layering of the soil profile can influence the accumulation of infiltrated water and the way in which subsurface runoff is formed. This paper examines a mountain podzol characterized by clearly developed soil horizons. After these horizons had been identified, distinct soil layers were defined (the eluvial horizon, the spodic horizon (undifferentiated), and weathered bedrock). Saturated hydraulic conductivity $\left(K_{s}\right)$, particle size distribution and bulk density were measured in these layers. A visualization of the distribution of infiltrated water in the podzolic profile was performed using a dye tracer experiment. The accumulation of dyed water and a distinct lateral flow were detected in the eluvial layer. Only limited entry of water into the spodic layer was observed. These effects were caused by changes in soil hydraulic properties (SHP) among the investigated layers. For the spodic horizons, the measured $K_{s}$ value (crucial SHP) was significantly lower than the $K_{s}$ values for the other tested horizons. The probable reason for the lower $K_{s}$ was an accumulation of fine particles and various substances in the spodic horizons, and corresponding changes in the porous system. The observed effects of layering indicate that water can be accumulated and subsurface runoff can be formed over the spodic layer during intensive rain or snow melting.
\end{abstract}

Keywords: Brilliant blue; Guelph permeameter; Field saturated hydraulic conductivity; Infiltration into layered soil; Mountain forest.

\section{INTRODUCTION}

The hydrological role of soil for water retention and for transforming precipitation into runoff is pivotal (Kutílek and Nielsen, 1994). Brilliant Blue FCF dye tracer (BB) has become a widely-used and popular tracer for visualizing water flow in a soil profile (e.g. Clark and Zipper, 2016; Kodešová et al., 2012; 2015; Qian et al., 2015; Sander and Gerke, 2007), due to its low toxicity (it is used as a food dye), good colour contrasts in most soils, and its reasonable cost (Laine-Kaulio et al., 2015). Although the dyed soil does not ideally represent the entire flow field, BB provides a useful indication of the preferential flow of the infiltrated water (Leibundgut et al., 2009; Schwen et al., 2014a).

For a physically-based description of soil-water flow, the crucial soil hydraulic parameters (SHP) are saturated hydraulic conductivity $\left(K_{s}\right)$ and the parameters of the retention curve (RETC) (Hillel, 1998; Rezaei et al., 2016). On the basis of knowledge of $K_{s}$ and RETC, unsaturated hydraulic conductivity can be expressed using an appropriate hydraulic model, e.g. Genuchten - Mualem (van Genuchten, 1980). If this approach is applied, $K_{s}$ and RETC values enable the water flow in unsaturated soils to be modelled using a numerical solution of the Richards equation (Kutílek and Nielsen, 1994). For sandy soils, pedotransfer functions (indirect methods) based on easily determinable soil properties (texture, bulk density) can be used with sufficient precision for estimating the hydrostatic parameter RETC (Vereecken et al., 2010). For estimates of the dynamic parameter $K_{s}$, pedotransfer functions usually exhibit serious errors (see Jarvis et al., 2013), because the value of $K_{s}$ is very sensitive to specific characteristics of the porous system (e.g. continuity and tortuosity of the porous system, the occurrence of macropores). Direct measurements of $K_{s}$ are therefore irreplaceable, although it is a very difficult task to measure $K_{s}$ properly (Bagarello et al., 2014, 2016; Jačka et al., 2014; Reynolds et al., 2000). The coefficient of variation (CV) of measured $K_{s}$ within a single soil layer is often higher than $100 \%$, even at the plot scale (Jačka et al., 2016, 2014; Webb et al., 2000). Parameter $K_{s}$ therefore exhibits high spatial variability (Fodor et al., 2011; Kutílek and Nielsen, 1994), and it is necessary to have a sufficient number of replicates in order to obtain a representative mean value of $K_{s}$ for each soil layer (Pennock et al., 2008).

Soil layering, which occurs to varying extents in the profiles of most soils, influences the distribution and accumulation of infiltrated water (Huang et al., 2011; Si et al., 2011; Zettl et al., 2011). Knowledge of the SHP of each soil layer is necessary for a correct understanding and for correct modelling of water flow in the layered profile (Shin et al., 2012; Swarowsky et al., 2011). As Schwen et al. (2014b) pointed out, unlike horizontal changes in SHP, vertical changes in SHP have not been sufficiently studied.

For distinctly-layered podzolic soils, possible water accumulation over a less permeable spodic layer is mentioned by $\mathrm{Ku}-$ tílek and Nielsen (1994). This lower permeability arises from an accumulation of fine particles and various substances in the spodic layer, and from a corresponding increase in the tortuosity and decrease in the size of the effective pores (Rezaei et al., 2016; Seuntjens et al., 2001; Wang and McKeague, 1982). However, for mountain podzols, insufficient number of studies (about water flow and accumulation, and changes in the crucial SHP among soil layers) has been reported in the literature. 
Moreover, areas dominated by mountain podzols are hydrologically very important, as these areas are characterized by very high average precipitation ( $>1600 \mathrm{~mm}$ year $^{-1}$, Pavlásek et al., 2009). Therefore, these areas have a strong impact on the hydrological situation in lower-located regions during extreme hydrological events (floods and also droughts).

This paper presents a visualization of the distribution of infiltrated water in the profile of a mountain haplic podzol using dye tracer experiments. The results of measurements of the key hydraulic parameter $K_{s}$, particle size distribution and bulk density are also presented for identified podzolic layers. The research questions are: 1) Is the flow of infiltrated water affected by the distinct layering of the investigated podzol, and 2) do the values of $K_{s}$ and related soil properties (texture and bulk density) differ among the identified layers? On the basis of these research questions and the motivation for our study as mentioned above, the following aims of the paper were formulated: 1) Reveal differences in $K_{s}$ and related soil properties among markedly different podzolic layers. 2) Investigate the effect of this layering on the redistribution of the infiltrated water using dye tracer experiments.

\section{MATERIAL AND METHODS Study site}

The investigation was performed on a study site dominated by a mountain podzol with distinct layers. This site occupies a small part of the Modrava 2 experimental catchment, which is described in Pavlásek et al. $(2009,2010)$ and in Jačka et al. (2012). The site is located in the high-altitude part of the Šumava National Park, near the Czech-German border (see Figure 1). A description of the site is also given by Jačka et al. (2012, 2014, 2016). The site is covered predominantly with the following plant species: Calamagrostis villosa, Picea abies, Avenella flexuosa, Vaccinium myrtillus, Luzula sylvatica, Athyrium distentifolium.

The study site is an area approx. 60 meters in diameter. The site is characterized by a low slope gradient (mean approx. $4 \%$ ) with north aspect, and is located in a saddle at an elevation of about $1270 \mathrm{~m}$. The shape of the slope is slightly convex (nearly uniform). Haplic podzol with distinctly differentiated eluvial and illuvial horizons is dominant throughout the site. The soil horizons of the examined podzol are depicted on the vertical cross-section in Figure 2. The mean thicknesses of the soil horizons (determined using boreholes made using a gouge auger close to the Guelph permeameter experiments and on the walls of an excavated pit - see the position in Figure 1) are as follows: organic horizon $\mathrm{O}$, together with humus horizon $\mathrm{Ah}$, $7.5 \mathrm{~cm}$; ash-gray bleached eluvial horizon E $12.5 \mathrm{~cm}$; illuvial spodic horizons Bhs together with Bs $40 \mathrm{~cm}$. Horizons $\mathrm{O}$ and $\mathrm{Ah}$, and also horizons Bhs and Bs, are not separated by sharp boundaries. The thicknesses and the soil properties are therefore described for these joint horizons as for a single soil layer. The bedrock $\mathrm{C}$, consisting of weathered metamorphic rocks sillimanite, migmatite and paragneiss, is relatively homogeneous fine-grained material.

\section{Sampling design}

Three distinctly different soil layers were defined in the examined podzol: 1) the eluvial horizon, 2) spodic horizons (undifferentiated), and 3) weathered bedrock. In each of these layers, selected soil properties $\left(K_{s}\right.$, particle size distribution and bulk density) were measured. Disturbed soil samples one liter in volume (for determining the particle size distribution) and

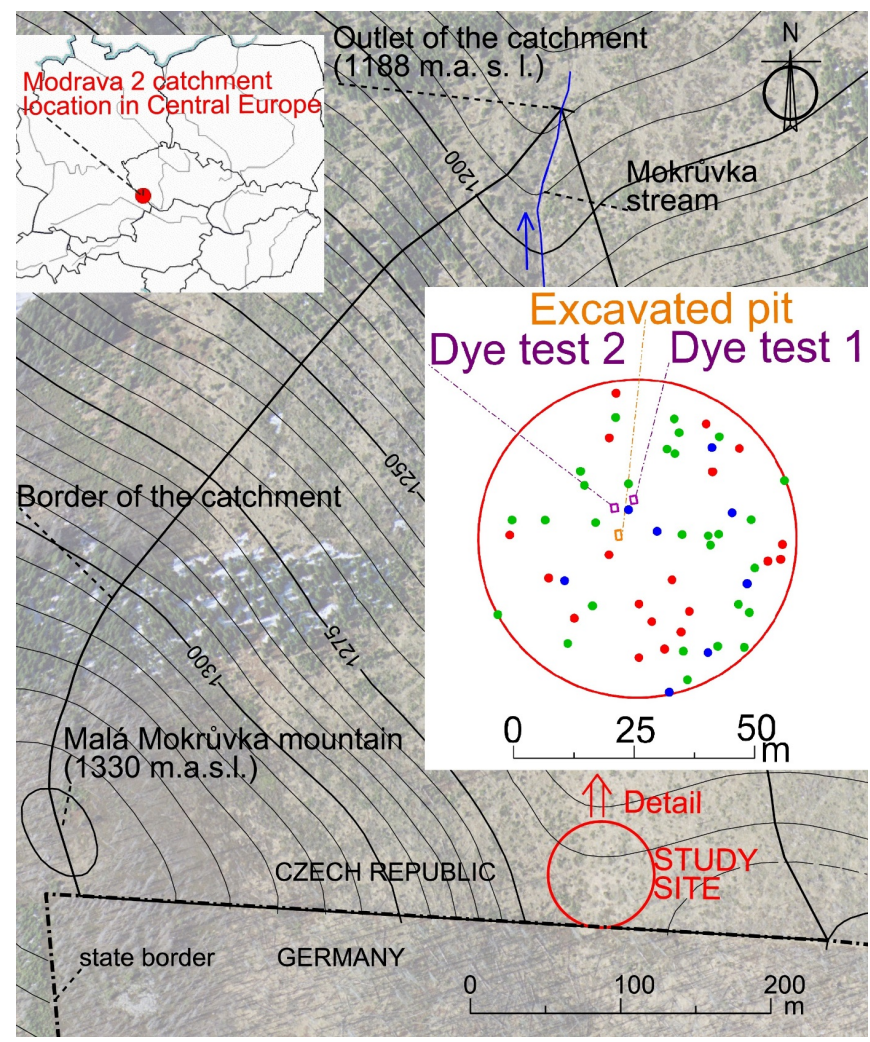

Fig. 1. Location of the study site in the catchment and in Central Europe (modified from Jačka et al. (2012)) and a detail of the sampling positions on the site. The points denote GP tests performed in the eluvial layer (green), the spodic layer (red), and the bedrock (blue).

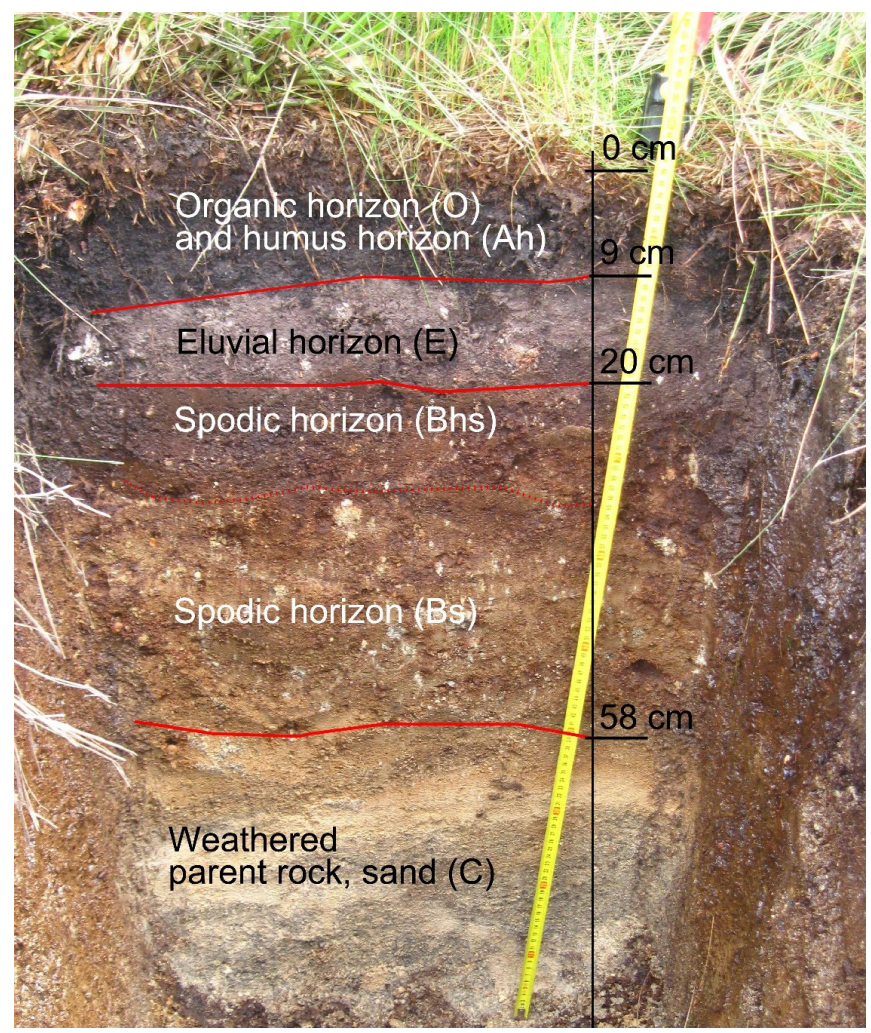

Fig. 2. Podzolic profile with the soil horizons described on the wall of an excavated pit. 
undisturbed samples $100 \mathrm{~cm}^{3}$ in volume (for determining the bulk density) were sampled during $K_{s}$ measurements at the centre of each layer for five replications.

To characterize the soil properties of each layer, measurements were planned to be randomly spatially distributed throughout the site. Random coordinates were generated in the $R$ software environment using the function runif (package stats, version 3.0.2). These coordinates were used as GPS locations of the sampling positions. Boreholes for the $K_{s}$ measurements were drilled at these positions (see the points in Figure 1). The random sampling approach was not completely met. Limitations of the random sampling approach included the following: 1) to avoid mutual interference of the experiments, the minimum distance of the sampling points was defined as $1.5 \mathrm{~m}$; 2) it was impossible to drill a borehole to the required depth at some locations, due to stones and roots in the profile and due to the occurrence of young trees and tree stumps on the soil surface. In cases when we were unable to drill a borehole at the randomly generated position, we drilled another borehole as close as possible to this original position. The coordinates of this alternative position were recorded for the further spatial statistical analysis. To characterize $K_{s}$ of the tested soil layers, a total of 28 Guelph permeameter (GP) infiltration measurements were carried out in the E horizon; 19 experiments in the Bhs and Bs spodic horizons, and 8 measurements in the weathered bedrock (the $\mathrm{C}$ horizon). Overall, owing to difficulties that occurred when deep wells were drilled in the stony heterogeneous soil, a smaller number of measurements were performed in deeper boreholes than in shallower boreholes. In addition, some boreholes (usually deeper holes) had to be excluded due to their irregular shape, which is inappropriate for GP measurements. Since the measurements were carried out in August, the measured data represents the growing season, characterized by strong vegetation activity and a high level of evapotranspiration.

\section{Determination of $K_{s}$ and related soil properties}

Field measurements of $K_{s}$ were performed using a Guelph permeameter (GP), which is a well-documented device (e.g. Bagarello, 1997; Elrick et al., 1989; Reynolds, 2008; Reynolds and Lewis, 2012). The standard measurement method that was applied is described in the operating instructions (Eijkelkamp, 2011). To avoid interference between measurements, an individual borehole was drilled for each GP test. No measurements were made at different depths in the same borehole. The water level $\left(h_{g}\right)$ in the well was kept constant at $16.5 \mathrm{~cm}$. The well $\left(r_{g}\right)$ was $3 \mathrm{~cm}$ in radius. Measurements were made until a quasisteady state $\left(i_{c g}\right)$ was reached (from 30 to $60 \mathrm{~min}$ ). Due to moderate variation, $i_{c g}$ was calculated as the average of the last three measured values. Because the sampling was done in sandy soil containing a small amount of clay particles, no smearing was observed in the wells.

The single constant head approach (Eq. (1)) was used to calculate $K_{s}$ (Elrick et al., 1989; Reynolds, 2008):

$$
K_{s}=\frac{C_{w} i_{c g} A_{g}}{2 \pi h_{g}^{2}+C_{w} \pi r_{g}^{2}+2 \pi h_{g} / s n}
$$

where $A_{g}$ is the cross-sectional area of the GP water reservoir, $C_{w}$ is the dimensionless well shape factor, $s n$ is the sorptive number (a value of $0.12 \mathrm{~cm}^{-1}$ was used on the basis of an investigation of the soil texture and structure). The value of $C_{w}$ was calculated according to Zhang et al. (1998).
To determine the bulk density, undisturbed soil samples were collected into stainless steel sample rings (volume of the sample $100 \mathrm{~cm}^{3}, 4.1 \mathrm{~cm}$ in length and $2.8 \mathrm{~cm}$ in inner radius, Eijkelkamp, NL). Subsequently, the samples were oven dried in the laboratory to a constant weight, and the bulk density was calculated (mass of dried soil [g] divided by volume of the sample $\left.\left[\mathrm{cm}^{3}\right]\right)$. The particle size analysis was performed using the hydrometer method (CEN ISO/TS 17892-4, 2004). The soil texture was classified according to the textural triangle of the United States Department of Agriculture (USDA).

\section{Statistical analysis}

Descriptive statistics were calculated for the three $K_{s}$ datasets (each representing one of the three defined soil layers). Normality tests (Shapiro and Wilk, 1965) were performed on the measured $K_{s}$ datasets and normality was rejected. For the decadic logarithms of the $K_{s}$ datasets, normality was accepted. Therefore, log-normal distributions were found to be suitable for the measured datasets, and one-way analysis of variance (ANOVA) and Tukey's Honestly Significant Difference test (TukeyHSD) were performed on the logarithms. The geometric mean is an appropriate mean for the log-normal distribution, and was used as a representative estimate of the central value of the measured data. The differences in $K_{s}$ among the soil layers were assessed using ANOVA. When a significant difference in means was indicated, TukeyHSD was carried out for multiple pairwise comparisons. Null hypotheses of ANOVA and TukeyHSD were tested at a significance level of 0.05 . The statistical tests were calculated using the Stats package (version 3.0.2), and the descriptive statistics were calculated using the Pastecs package (version 1.3-15) in the R software environment.

For the log-transformed $K_{s}$ datasets, spatial dependencies were also investigated using an experimental semivariogram. The following theoretical models were fitted to this semivariogram: exponential, Gaussian, linear, nugget. A description of the semivariogram used here and the fitted models is given by $\mathrm{Hu}$ et al. (2013); Marín-Castro et al. (2016); NegreteYankelevich and Fox (2015). The quality of fit was assessed using the Nash-Sutcliffe (NASH) model efficiency coefficient (Nash and Sutcliffe, 1970). The differences among models were assessed using the Akaike Information Criterion (AIC) (Sakamoto et al., 1986). No spatial dependencies were indicated (no apparent trend in semivariance was observed). The measured $K_{s}$ values for each soil layer were therefore considered as randomly spatially distributed, and were treated using a classical statistical approach.

\section{Dye tracer tests}

The redistribution of the infiltrated water in the podzolic profile was visualized using a dye tracer (Brilliant Blue FCF, referred to here as $\mathrm{BB}$ ). Two single-ring infiltration tests were performed (see the positions in Figure 1). The mutual distance of the two tests was approx. 4 meters and therefore, the tests represent practically the same position on the slope. A single ring $(30 \mathrm{~cm}$ in diameter for the first test and $28 \mathrm{~cm}$ in diameter for the second test) was inserted to a depth of about $12.5 \mathrm{~cm}$, and the lower sharpened edge of the ring was located in the upper part of the $\mathrm{E}$ horizon. The impact of the $2 \mathrm{~cm}$ difference in the diameter on the water distribution in the podzolic profile was considered negligible. The slightly different diameters were used as exactly the same rings were not available at the same time (tests were performed during the same day). The soil surface inside the ring was flooded to a depth of approx. $4 \mathrm{~cm}$ 
using dyed water, and the water level (i.e. the pressure head $4 \mathrm{~cm}$ ) was kept approximately constant for 2 hours. The amount of water applied (controlled by maintaining the practically constant pressure head for 2 hours) was determined to ensure the quasi-steady infiltration rate conditions and to saturate the soil profile sufficiently (to reveal the effect of the interface of the spodic and the eluvial layer). The undisturbed soil core samples $\left(100 \mathrm{~cm}^{3}\right)$ were collected before the infiltration tests (to define the initial volumetric soil water content) and after the tests during an excavation of the soil profile (to define the volumetric soil water content after the tests). Mean values of the initial water content were 39 Vol.- $\%$ for the eluvial layer and 40 Vol.- $\%$ for the spodic layer. Mean values of the water content determined after the tests were $45 \mathrm{Vol} .-\%$ for the eluvial layer and 42 Vol.- $\%$ for the spodic layer. The tracer was applied in a water solution of $5 \mathrm{~g}^{-1}$ (Schwen et al., 2014a).

The soil profile (a vertical cross-section through the center of the previously flooded area and horizontal cross-sections at various depths from 10 to $40 \mathrm{~cm}$ below the surface) was excavated 24 hours after the soil surface inside the ring had been flooded. A visual inspection of the soil was performed on the walls of the cross-sections and photos were taken. The dyed areas in the cross-sections were mapped in the field, and the distances and the sizes of these areas were measured using a measuring tape. Additionally, the sizes and the shapes of the dyed areas were visually inspected using photos depicting the dyed soil and the measuring tape as a scale.

\section{RESULTS AND DISCUSSION}

\section{Values of $K_{s}$ and related properties for the soil layers}

A description of the soil texture, bulk density and porosity for the identified podzolic layers is given in Table 1. Particle size analysis showed that the spodic layer contained a greater amount of clay $(+6 \%)$ and silt $(+12 \%)$ than the E horizon. The percentage of gravel $(>2 \mathrm{~mm})$ was practically the same for both layers (approx. 30\%). According to Wang and McKeague (1982), the increase in content of fine particles can be caused by illuviation of fine particles, which were translocated from the E horizon by infiltrated water together with other substances (humic substances, sesquioxides, chelates), or by synthesis of the new clay minerals from translocated weathering products formed in a strongly acidic environment, which is typical for podzols (e.g. Jankowski, 2014; Waroszewski et al., 2016). Lateral podsolization on the slope (described e.g. in Sommer et al. (2001) or Jankowski (2014)) can also decrease the amount of fine particles contained in the eluvial layer (study site is located in the upper part of the slope in the saddle).

Higher amount of clay in the spodic podzolic layer than in the eluvial layer is a concomitant characteristic of the podzolization process (Sommer et al., 2001), although this characteristic is sometimes not present in podzols due to specific soil conditions (see Waroszewski et al., 2016). The estimated bulk density for the $\mathrm{E}$ horizon is $1.4 \mathrm{~g} \mathrm{~cm}^{-3}$, and the calculated porosity is $46 \%$ (using the bulk density and mean density of the solid particles). These values are similar for the spodic layer: $1.3 \mathrm{~g} \mathrm{~cm}^{-3}$ and $47 \%$, respectively. The slightly lower bulk density of the spodic layer may be caused by volumetric expansion of accumulated organic matter translocated from the horizons located above (Jersak et al., 1995; Sommer et al., 2001).

Differences in the means, medians, $\mathrm{CV}$, minima and maxima of the measured $K_{s}$ datasets were noted (see the descriptive statistics in Table 2 and Figure 3). For the tested layers, the ratios of the geometric means of the measured $K_{s}$ datasets were as follows: $\mathrm{C}$ horizon: spodic horizons -5.52 , E horizon: spodic horizons $-2.87, \mathrm{C}$ horizon: E horizon -1.92 . The lowest median,

Table 1. Soil characteristics of the identified podzolic layers (mean $\pm \mathrm{SD}, \mathrm{n}=5$ ).

\begin{tabular}{|c|c|c|c|c|}
\hline \multirow[t]{2}{*}{ Parameters } & \multirow[t]{2}{*}{ Units } & \multicolumn{3}{|c|}{ Identified layer (horizon or group of horizons) } \\
\hline & & Eluvial (E) & Spodic (Bhs and Bs) & Bedrock (C) \\
\hline Clay $^{\mathrm{a}}(<2 \mu \mathrm{m})$ & $\%$ (weight) & $1 \pm 0.5$ & $7 \pm 2.1$ & $8 \pm 1.4$ \\
\hline $\operatorname{Silt}^{\mathrm{a}}(2-50 \mu \mathrm{m})$ & $\%$ (weight) & $20 \pm 8.6$ & $32 \pm 4.0$ & $22 \pm 4.0$ \\
\hline $\operatorname{Sand}^{\mathrm{a}}(0.05-2 \mathrm{~mm})$ & $\%$ (weight) & $79 \pm 9.2$ & $61 \pm 3.5$ & $70 \pm 2.8$ \\
\hline Gravel $(>2 \mathrm{~mm})$ & $\%$ (weight) & $32 \pm 11.0$ & $30 \pm 9.0$ & $25 \pm 10.3$ \\
\hline USDA classification & & loamy sand & sandy loam & sandy loam \\
\hline Bulk density & g.cm ${ }^{-3}$ & $1.39 \pm 0.09$ & $1.31 \pm 0.07$ & $1.40 \pm 0.04$ \\
\hline Porosity ${ }^{\mathrm{b}}$ & $\%$ (volume) & 46 & 48 & 47 \\
\hline
\end{tabular}

${ }^{\text {a }}$ Percentages of these soil fractions were calculated from particles $<2 \mathrm{~mm}$.

${ }^{\mathrm{b}}$ Values calculated using the bulk density and pycnometrically determined density of the solid particles.

Table 2.A statistical description of the saturated hydraulic conductivity $K_{s}$ measured in different podzolic layers; the different letters following the means indicate significant differences between layers (TukeyHSD test at $\alpha=0.05$ ).

\begin{tabular}{|c|c|c|c|c|}
\hline \multirow[t]{2}{*}{ Parameters } & \multirow[t]{2}{*}{ Units } & \multicolumn{3}{|c|}{ Depths of boreholes [cm], dominantly sampled layer } \\
\hline & & 19-26, Eluvial & 30-56, Spodic & $68-130$, Bedrock \\
\hline Geometric mean & $\mathrm{m} \cdot \mathrm{s}^{-1} \times 10^{-6}$ & 4.415 & 1.540 & 8.495 \\
\hline Arithmetic mean & $\mathrm{m} \cdot \mathrm{s}^{-1} \times 10^{-6}$ & 6.341 & 1.863 & 11.659 \\
\hline Standard deviation & $\mathrm{m} \cdot \mathrm{s}^{-1} \times 10^{-6}$ & 5.804 & 1.284 & 8.130 \\
\hline Median & $\mathrm{m} \cdot \mathrm{s}^{-1} \times 10^{-6}$ & 4.980 & 1.469 & 9.633 \\
\hline Minimum & $\mathrm{m} \cdot \mathrm{s}^{-1} \times 10^{-6}$ & 0.905 & 0.618 & 1.041 \\
\hline Maximum & $\mathrm{m} \cdot \mathrm{s}^{-1} \times 10^{-6}$ & 25.800 & 5.493 & 25.888 \\
\hline Coefficient of variation & $\%$ & 92 & 69 & 70 \\
\hline Range $^{\mathrm{a}}$ & & 1.455 & 0.949 & 1.396 \\
\hline Arithmetic mean ${ }^{\mathrm{a}}$ & & $-5.355 \mathbf{a}$ & $-5.812 \mathbf{b}$ & $-5.071 \mathbf{a}$ \\
\hline Standard deviation $^{\mathrm{a}}$ & & 0.390 & 0.269 & 0.435 \\
\hline CI mean $0.95^{\mathrm{a}, \mathrm{b}}$ & & 0.151 & 0.130 & 0.364 \\
\hline Median $^{\mathrm{a}}$ & & -5.303 & -5.833 & -5.019 \\
\hline No. of experiments & & 28 & 19 & 8 \\
\hline
\end{tabular}

${ }^{\text {a }}$ Parameters of decadic log-transformed datasets.

${ }^{\mathrm{b}}$ The confidence interval of the arithmetic mean calculated at the 0.95 significance level. 


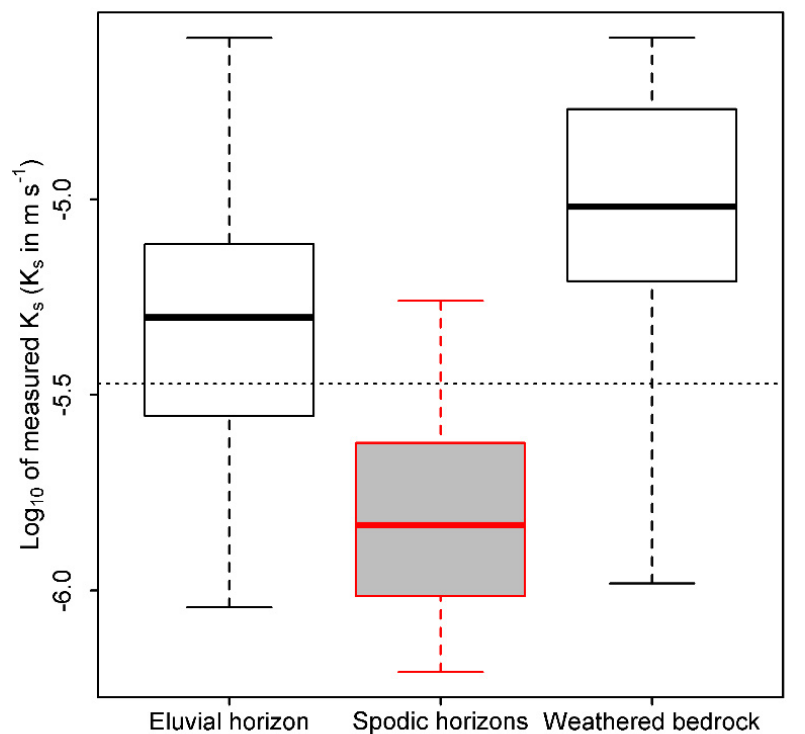

Fig. 3. Boxplots (sample minimum, first quartile, median, third quartile, maximum) of the decadic log-transformed estimates of $K_{s}$ values $\left[\mathrm{m} \mathrm{s}^{-1}\right]$ for the different podzolic horizons. The dotted line shows the average of all measured data and the red/grey colour of the boxplot illustrates a significantly lower mean.

minimum and maximum of the $K_{s}$ values were measured for illuvial spodic horizons. The highest $\mathrm{CV}$ value was measured for horizon $\mathrm{E}$ where its value was more than $20 \%$ higher than in the other tested soil layers (see Table 2). The highest CV value may have been caused by greater local heterogeneity in this layer (due to the roots of various plants and remnants of dead wood, which were encountered predominantly in the E horizon). The first quartile, the median, the third quartile, and the maximum of the decadic log-transformed values of $K_{s}$ measured in the spodic horizons were distinctly lower than for other tested layers (see a graphical comparison with the surrounding layers in Figure 3).

A significant difference between means was found using the ANOVA test applied to the decadic log-transformed $K_{s}$ datasets, and the null hypothesis was rejected $\left(p\right.$-value $\left.=7.46 \times 10^{-6}\right)$. According to the subsequent TukeyHSD test, significant differences in the means of the log-transformed $K_{s}$ values were found for the following pairs: E horizon and spodic horizons ( $p$-value $\left.=2.38 \times 10^{-4}\right)$, and $\mathrm{C}$ horizon and spodic horizons ( $p$-value $=$ $3.00 \times 10^{-5}$ ). For the pair of $K_{s}$ datasets collected in the $\mathrm{E}$ horizon and in the $\mathrm{C}$ horizon, the means of the log-transformed values were not different according to the Tukey HSD test ( $p$-value $=$ $0.130)$.

The lower $K_{s}$ values measured for the spodic horizons are obviously related to changes in the porous system. These changes in the porous system can be caused by the different content of fine particles (see the above-mentioned increase in clay and silt content in the spodic layer in comparison with the eluvial layer). Another reason for these changes can be an accumulation of various substances (organic matter, $\mathrm{Al}$ and $\mathrm{Fe}$ oxides and complexes of these oxides with organic acids chelates) in the spodic horizon. Translocation of these substances from the upper E horizon to spodic horizons by intensive water infiltration in acidic soil conditions is a characteristic of the podzolization process (Lundström et al., 2000; Sommer et al., 2001; Waroszewski et al., 2016). Illuviated substances form coatings inside the pores (Jankowski, 2014). These coatings, together with translocated fine particles, can

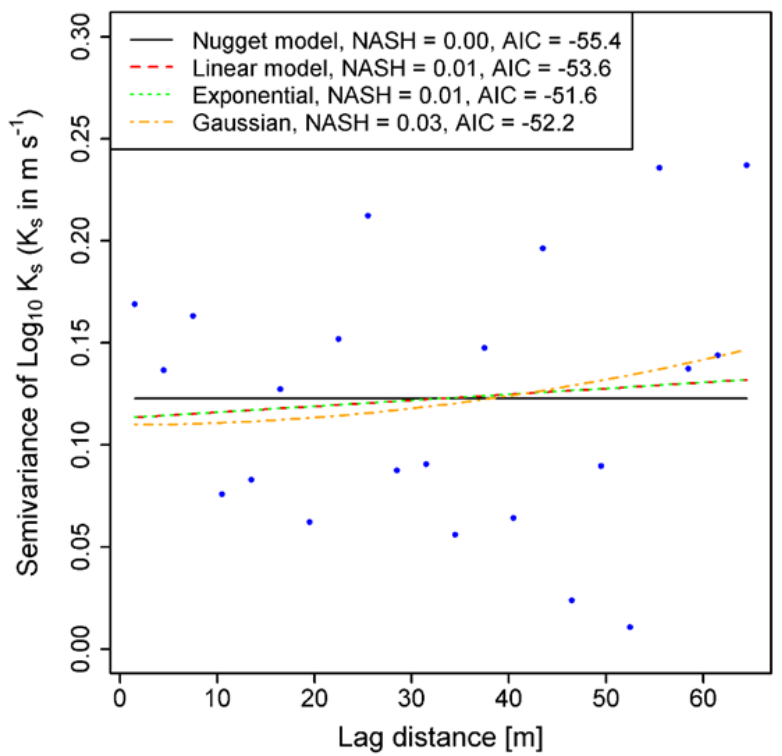

Fig. 4. Spatial dependency of $K_{\mathrm{s}}$ values measured in the E horizon tested using an experimental semivariogram and fitted models. The black solid horizontal line shows the nugget model.

cause clogging or partial blocking of effective pores, reduce the cross-sectional area of the effective pores, increase tortuosity and, as a consequence, slow down the water flow and reduce $K_{s}$.

For an illuvial cemented layer of an agriculturally-managed lowland arenic podzol, Rezaei et al. (2016) also found lower mean $K_{s}$ values than for the layer below and the layer above, using two different methods. Rezaei et al. (2016) pointed out that lower $K_{s}$ of the illuvial (spodic) layer located at a depth of $47-52 \mathrm{~cm}$ could be also partially caused by compaction by heavy machinery. Seuntjens et al. (2001) measured $K_{s}$ using a pressure infiltrometer in horizons of two different lowland podzols, i.e., a drier podzol, characterized by a lower situated groundwater level and a sharply-defined spodic horizon; and a wetter podzol with a diffuse spodic horizon located in an old land dune landscape covered with spots of vegetation of various types. For the spodic illuvial horizons of the two podzols, considerably lower mean $K_{s}$ values were also noted than for the surrounding horizons.

$K_{s}$ spatial dependencies were also investigated. See a representative example in Figure 4. The experimental semivariogram represents a cloud of points, and the fitting quality of all theoretical models is therefore low. See the NASH values in Figure 4. Moreover, the lowest value of AIC was indicated for the nugget model (Figure 4). All of these findings indicate no obvious trend in semivariance and no apparent spatial dependencies. The $K_{s}$ values for each podzolic layer can therefore be treated as a randomly horizontally distributed variable, and the best estimate for the entire site is the appropriate mean (the geometric mean, due to the log-normal distribution of the datasets).

The following reasons can be offered why no spatial dependencies were detected on a plot scale. 1) High local heterogeneity of the tested mountain forest soil (due to the occurrence of rocks, decaying dead wood and the roots of various plants in the profile) and the corresponding occurrence of preferential flow and other irregularities in the geometry of the flow field. 2) Subjective variability arising from the use of the GP method (a relatively small sampling volume, and possible influence of the soil during drilling). The local heterogeneity, together with the subjective variability, can introduce "noise" into measured 
data, can increase the overall variability of $K_{s}$, and can mask the spatial patterns. Marín-Castro et al. (2016) also did not find the expected spatial dependencies at the plot scale, probably for the reasons mentioned above.

The representativeness of the GP method was tested for the specific conditions of the investigated podzol by Jačka et al. (2014). For the E horizon, the GP method yielded a nonsignificantly different mean of $K_{s}$ in comparison with the single ring infiltrometer method (field estimate $K_{s}$ ), and a slightly lower mean value (1.6 times lower) than a laboratory permeameter applied to the undisturbed soil cores.

\section{Dye tracer visualisation of water flow}

The redistribution of the $\mathrm{BB}$ dyed water (which infiltrated through the surface inside the single ring infiltrometer) indicated that most of the infiltrated water was accumulated in the $\mathrm{E}$ horizon, and just a small portion of this water was distributed into the spodic layer (see dyed area in Table 3). Distinct lateral flow of the dyed water was detected in the E horizon. The distribution of the dyed water at different depths of the podzolic profile beneath the infiltrometer is shown in Figures 5 and 6 . In Figure 5, the cross-section at a vertical depth of $20 \mathrm{~cm}$ shows that the predominant part of the dyed water is located in the $\mathrm{E}$ horizon. The cross-section at a vertical depth of $30 \mathrm{~cm}$ shows only a few small colored areas, which are located in the spodic layer. The distinct effect of the layer interface (eluvial and spodic) is shown in a vertical cross section (Figure 5a). In the lower left corner of Figure $5 \mathrm{~b}$, there is a blue dye staining located in the upper part of the spodic layer close to the large rock. Possible explanation is that this rock blocked a lateral flow on the layer interface (see Figure 5a) and redirected the water flow to the deeper spodic layer.

In Figure 6, dyed areas can be detected in the E horizon, even at a horizontal distance greater than $30 \mathrm{~cm}$ from the centre of the infiltrometer (an indication of distinct lateral flow), and the cross-section in the spodic layer again shows only a few small colored areas.

The observed dyed patterns in the layered profile correspond to the measured significant decrease in $K_{s}$ in the spodic layer. However, it should be mentioned here that the dyed soil patterns do not match the water flow patterns exactly, because dissolved $\mathrm{BB}$ exhibits problematic sorption effects and lower mobility than untreated water in smaller-sized pores (Fér et al., 2016; Nobles et al., 2010; Wang and Zhang, 2011). Nevertheless, the areas dyed by BB usefully visualize the major flow field in the soil profile (Jiang et al., 2017; Leibundgut et al., a)

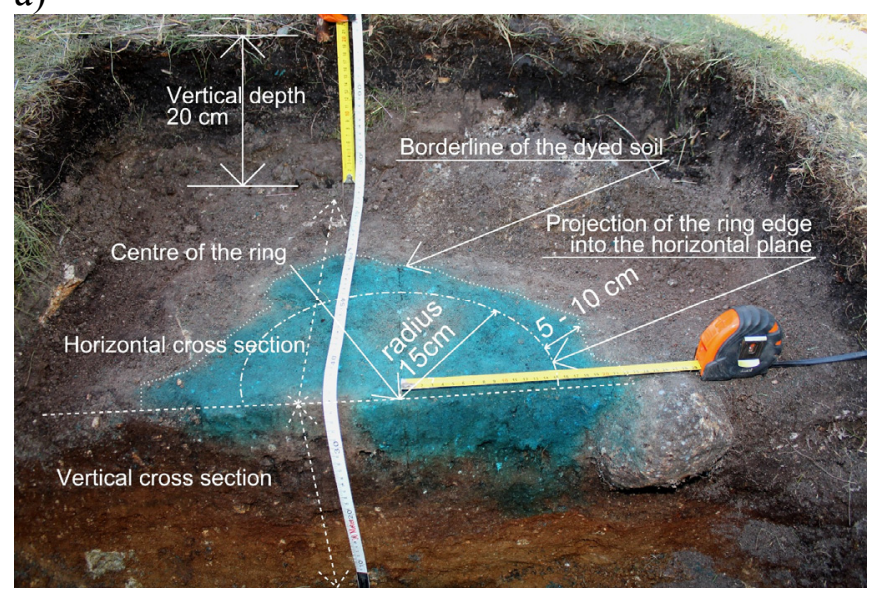

b)

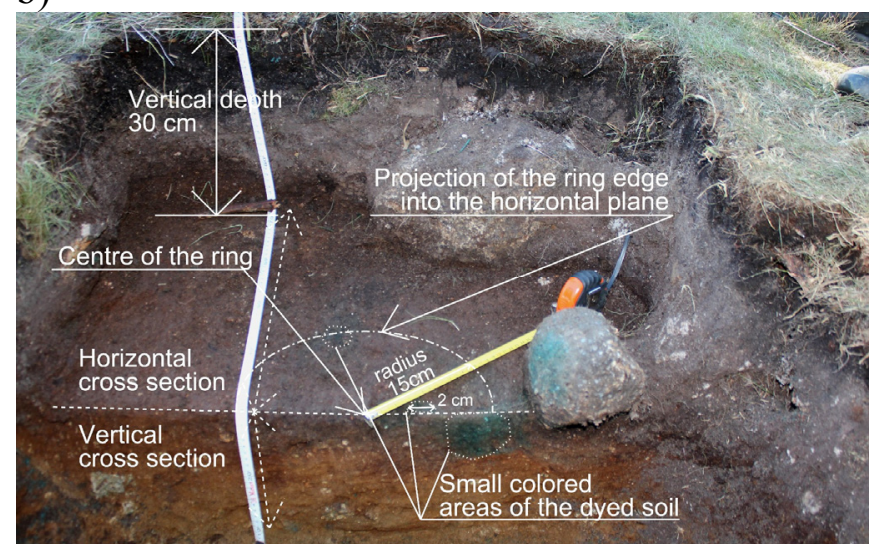

Fig. 5. Distribution of the infiltrated water below single ring infiltration test No. 1, visualized using a BB tracer - (a) the horizontal cross-section at a vertical depth of $20 \mathrm{~cm}$ (above), and (b) the horizontal cross-section at a vertical depth of $30 \mathrm{~cm}$ (below).

2009). For the examined profile, the BB experiments revealed distinct differences among the soil layers in hydrologically important pores (macropores and upper size capillary pores, where the preferential flow occurs). According to the flow field of the dyed water, the major interconnected part of these pores is located in the E horizon, and the vertical connection of these pores in the soil profile is interrupted in the spodic layer.

Table 3. Horizontal and vertical spread of the BB dye tracer in the examined soil layers.

\begin{tabular}{|c|c|c|c|c|c|c|c|}
\hline BB test & $\begin{array}{c}\text { Layer (horizon or group } \\
\text { of horizons) }\end{array}$ & $\begin{array}{l}\text { Thickness of the } \\
\text { layer }[\mathrm{cm}]\end{array}$ & $\begin{array}{l}\text { Thickness of the } \\
\text { dyed soil }[\mathrm{cm}]^{\mathrm{a}}\end{array}$ & Shape of the dyed patterns & $\begin{array}{c}\text { Vertical } \\
\text { depth } \\
{[\mathrm{cm}]^{b}}\end{array}$ & $\begin{array}{c}\text { Horizontal } \\
\text { distance } \\
{[\mathrm{cm}]^{\mathrm{c}}} \\
\end{array}$ & $\begin{array}{l}\text { Dyed area } \\
{\left[\mathrm{cm}^{2}\right]^{\mathrm{d}}}\end{array}$ \\
\hline \multirow{2}{*}{1} & Horizon E & from 9 to 20 & 16 & $\begin{array}{l}\text { Large interconnected dyed area } \\
\text { with undyed soil patterns }\end{array}$ & 20 & 30 & 1500 \\
\hline & $\begin{array}{l}\text { Spodic layer (horizon } \\
\text { Bhs together with Bs) }\end{array}$ & approx. 39 & 7 & $\begin{array}{l}\text { A few separate stains of small } \\
\text { size }(\max .6 \mathrm{~cm})\end{array}$ & 30 & 27 & 100 \\
\hline \multirow{2}{*}{2} & Horizon E & from 11 to 21 & 18 & $\begin{array}{l}\text { Large interconnected dyed area } \\
\text { with undyed soil patterns }\end{array}$ & 18 & 48 & 1100 \\
\hline & $\begin{array}{l}\text { Spodic layer (horizon } \\
\text { Bhs together with Bs) }\end{array}$ & approx. 42 & 2 & $\begin{array}{l}\text { A few separate stains of small } \\
\text { size }(\max .3 \mathrm{~cm})\end{array}$ & 30 & 29 & 50 \\
\hline
\end{tabular}

\footnotetext{
${ }^{\mathrm{a}}$ Maximum vertical thickness.

${ }^{b}$ Vertical depth (from the surface) of the horizontal cross-section with the maximum horizontal spread of the dye.

${ }^{c}$ Distance of the maximum horizontal spread of the dye measured from the vertical axis of the ring.

${ }^{\mathrm{d}}$ Estimated size of the dyed area in the horizontal cross-section with the largest spread of the dye.
} 
a)

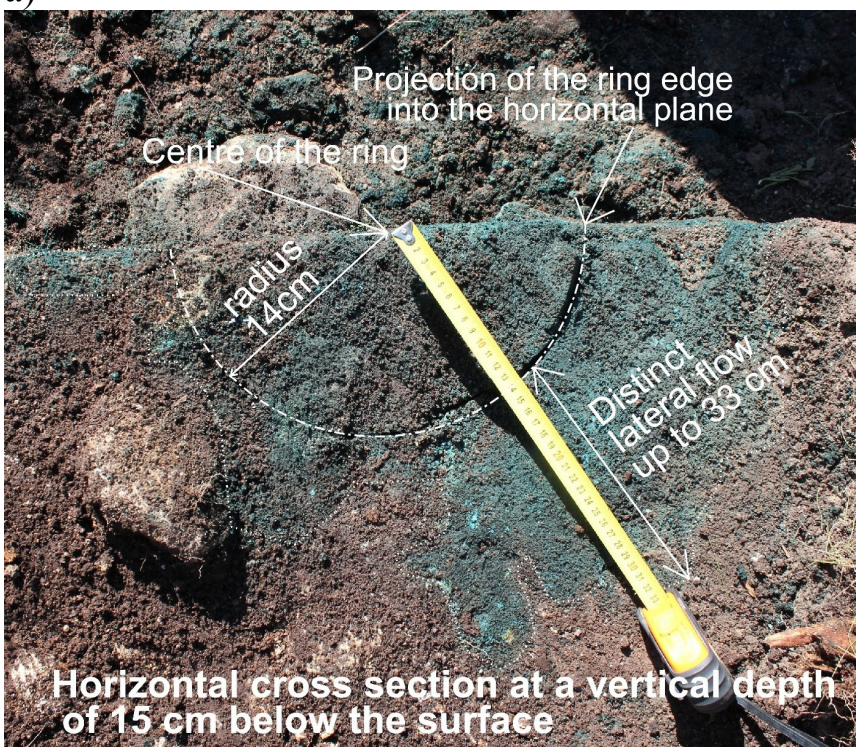

b)

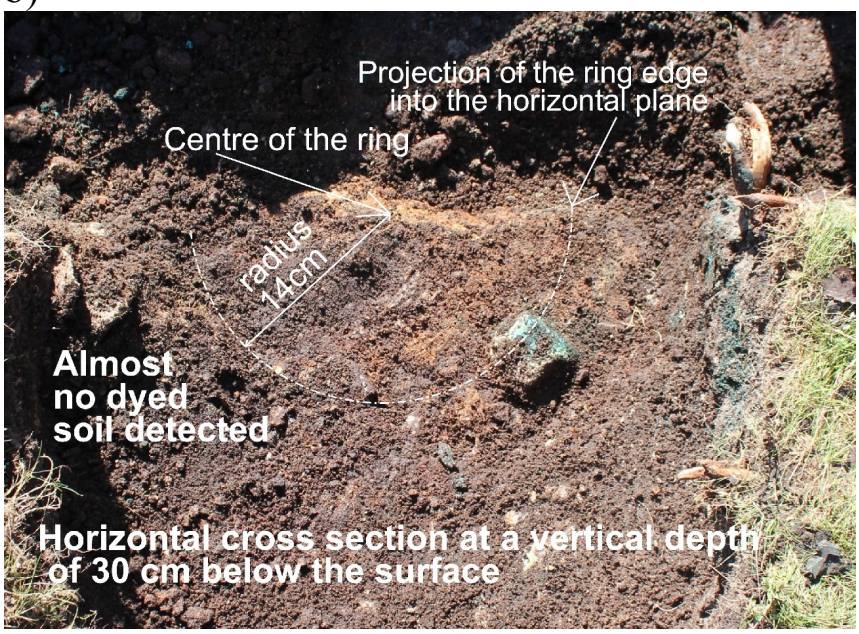

c)

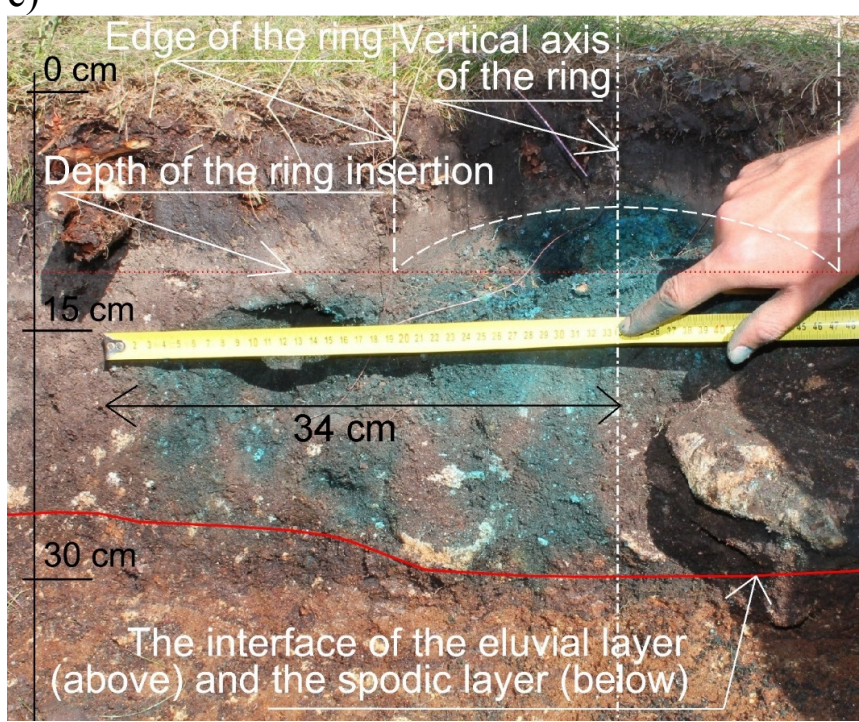

Fig. 6. Distribution of the infiltrated water below single ring infiltration test No. 2, visualized using a BB tracer - (a) the horizontal cross-section at a vertical depth of $15 \mathrm{~cm}$, (b) the horizontal cross-section at a vertical depth of $30 \mathrm{~cm}$, (c) corresponding detail on the vertical cross section through the centre of the ring.

\section{Limitations of the research}

For an investigation of the hydrological effects of the podzolic profile, we selected a small area of the site, rather than selecting the entire catchment area. The described hydrological behavior may therefore not be valid for podzolic profiles with less distinct layers that occur in lower parts of the catchment. The small area of the site was selected due to 1) the occurrence of a distinctly layered haplic podzol throughout the site, and 2) the time-demanding nature of direct field measurements of $K_{s}$ in a rather inaccessible heterogeneous podzol. Parameter $K_{s}$ is the key soil property affecting soil water flow, and is unfortunately very difficult to measure properly (see Fodor et al., 2011). We have decided for a detailed characterization of $K_{s}$ including higher number of collected samples on a small site in well-developed soil layers.

For the infiltration measurement, we have used wellestablished field methods which sample small volume of the soil. We have selected these small-scale methods because they require relatively small soil disturbances, are easy to operate and exhibit low water consumption which is a very important aspect for hardly this accessible site without water supply. The examined site is located in the valuable central part of the Šumava National Park, where excavations and other soil disturbances should be minimized. Larger volume sampling methods such as for a rainfall simulator or large infiltrometer are theoretically more suitable for the examined heterogeneous soil but are also impracticable in this specific case due to the reasons mentioned above. To account for large stones (see their sizes in Figures 5 and 6) for particle size and bulk density measurements, large excavations would also be required. Therefore, these stones were not included in the analysis.

\section{Engineering implications}

After heavy rainfalls, water filling of empty shallow boreholes (formed during the GP tests) was observed. Some of these boreholes were flooded to a few centimetres below the surface of the soil. Dye tracer tests also indicated an accumulation of infiltrated water and lateral flow on the layer interface in the $\mathrm{E}$ horizon over the spodic layer (see Figures 5 and 6 and Table 3 ). Significantly lower $K_{s}$ was measured in the spodic layer (see Table 2 and Figure 3), and this corresponds to the findings mentioned above. Therefore, the spodic layer can probably form a hydraulic barrier under field-saturated conditions as it is indicated by the two different infiltration methods (GP and dye tracer tests) and by the observations of the water-level in the shallow boreholes after the heavy rainfalls.

As Si et al. (2011) pointed out, shallow subsurface runoff (lateral flow) on the layer interface can be formed when hydraulically different layers occur on a slope. According to Sommer et al. (2001), about $30 \%$ of the discharge is formed by this lateral flow denoted here as interflow in a sandstone podzolic catchment. For mountain podzols, waterlogging in the $\mathrm{E}$ horizon and water flow at the layer interface ( $\mathrm{E}$ and spodic layer) were observed by Waroszewski et al. (2016). The results of our study also clearly show the important role of layering on lateral flow and water accumulation in mountain podzols. For correct hydrological modelling, the effect of layering should be implemented for the examined soil. Using the measured $K_{s}$ values and RETC estimated indirectly from pedotranfer functions based on the measured soil texture and bulk density for identified layers, the water flow in the layered podzol investigated here can be modelled using specialized software, e.g. DRUtES (Kuráž et al., 2015), Hydrus (Šimůnek et al., 2016), and others. 
The layering of a mountain podzol can strongly affect the distribution of infiltrated water in the soil profile

\section{CONCLUSION}

The findings presented here are a contribution to knowledge about the hydrological behaviour of mountain haplic podzols. For this hydrologically important soil, vertical changes in the crucial hydraulic parameter $K_{s}$ among identified soil layers have been quantified, and the effect of the layering of the soil profile on the redistribution of infiltrated water has been assessed using dye tracer tests. A relatively large number of point-scale well-infiltration experiments showed significantly lower mean $K_{s}$ values for the spodic illuvial horizons than for the surrounding horizons. Reasons for the lower $K_{s}$ were probably an accumulation of fine particles and various substances in the spodic horizons, which were translocated from the abovelocated eluvial horizon during the podzolization process. The translocated substances and fine particles can form coatings on the soil solid phase and partially block the effective pores.

A strong effect of the interface between the eluvial layer and the spodic layer on the distribution of the infiltrated water was detected by dye tracer experiments, and this finding corresponds with the measured decrease in $K_{s}$ in the spodic layer. During heavy rainfall, the observed distinct lateral flow and water accumulation on the interface of these layers can cause water accumulation and the subsequent formation of shallow subsurface runoff if the interface is located on a slope. The predictions of hydrological models for areas dominated by mountain haplic podzols can be made more accurate by applying quantifications of $K_{s}$ and by using information about water flow directions from the dye tracer tests presented here. Due to the differently layered podzolic profiles that usually occur in mountain catchments (different thicknesses of the layers and different intensity of podzolization), further infiltration experiments and runoff observations in other sites are needed in order to provide an accurate description of the impact of podzolic layers on water flow on a larger scale.

Acknowledgements. We gratefully acknowledge support from the Internal Grant Agency of the Faculty of Environmental Sciences, Czech University of Life Sciences Prague, within the framework of Projects Nos. 20124252, 2011422003143, 20174223. We would also like to express our gratitude to the anonymous reviewers for their helpful comments.

\section{REFERENCES}

Bagarello, V., 1997. Influence of well preparation on fieldsaturated hydraulic conductivity measured with the Guelph Permeameter. Geoderma, 80, 169-180.

Bagarello, V., Baiamonte, G., Castellini, M., Di Prima, S., Iovino, M., 2014. A comparison between the single ring pressure infiltrometer and simplified falling head techniques. Hydrol. Process., 28, 4843-4853.

Bagarello, V., Iovino, M., Lai, J., 2016. Testing steady-state analysis of single-ring and square pressure infiltrometer data. Geoderma, 261, 101-109.

CEN ISO/TS 17892-4, 2004. Geotechnical Investigation and Testing - Laboratory Testing of Soil - Part 4: Determination of Particle Size Distribution. Inštitut za standardizacijo, Ljubljana, Slovenija.

Clark, E.V., Zipper, C.E., 2016. Vegetation influences nearsurface hydrological characteristics on a surface coal mine in eastern USA. Catena, 139, 241-249.

Eijkelkamp, 2011. Operating instructions. 09.07 Guelph permeameter. https://www.eijkelkamp.com/download.php?fi le=b2082939, 11/2011, accessed: 22/06/2016.
Elrick, D.E; Reynolds, W.D., Tan, K.A., 1989. Hydraulic conductivity measurements in the unsaturated zone using improved well analyses. Ground Water Monit. Rev., 9, 184193.

Fér, M., Leue, M., Kodešová, R., Gerke, H.H., Ellerbrock, R.H., 2016. Droplet infiltration dynamics and soil wettability related to soil organic matter of soil aggregate coatings. J. Hydrol. Hydromech., 64, 111-120.

Fodor, N., Sándor, R., Orfanus, T., Lichner, L., Rajkai, K., 2011. Evaluation method dependency of measured saturated hydraulic conductivity. Geoderma, 165, 60-68.

Hillel, D., 1998. Environmental Soil Physics. Academic Press, San Diego, USA, $771 \mathrm{p}$.

Hu, W., Shao, M., Wang, Q., She, D., 2013. Effects of measurement method, scale, and landscape features on variability of saturated hydraulic conductivity. J. Hydrol. Eng., 18, 4, 378-386.

Huang, M., Barbour, S.L., Elshorbagy, A., Zettl, J.D., Si, B.C., 2011. Water availability and forest growth in coarse-textured soils. Can. J. Soil Sci., 91, 199-210.

Jačka, L., Pavlásek, J., Jindrová, M., Bašta, P., Černý, M., Balvín, A., Pech, P., 2012. Steady infiltration rates estimated for a mountain forest catchment based on the distribution of plant species. J. For. Sci., 58, 536-544.

Jačka, L., Pavlásek, J., Kuráž, V., Pech, P., 2014. A comparison of three measuring methods for estimating the saturated hydraulic conductivity in the shallow subsurface layer of mountain podzols. Geoderma, 219-220, 82-88.

Jačka, L., Pavlásek, J., Pech, P., Kuráž, V., 2016. Assessment of evaluation methods using infiltration data measured in heterogeneous mountain soils. Geoderma, 276, 74-83.

Jankowski, M., 2014. The evidence of lateral podzolization in sandy soils of northern Poland. Catena, 112, 139-147.

Jarvis, N., Koestel, J., Messing, I., Moeys, J., Lindahl, A., 2013. Influence of soil, land use and climatic factors on hydraulic conductivity of soil. Hydrol. Earth Syst. Sci., 17, 5185-5195.

Jersak, J., Amundson, R.G., Brimhall Jr., G., 1995. A mass balance analysis of podzolization: examples from the northeastern United States. Geoderma, 66, 15-42.

Jiang, X.J., Liu, S., Zhang, H., 2017. Effects of different management practices on vertical soil water flow patterns in the Loess Plateau. Soil and Tillage Research, 166, 33-42.

Kodešová, R., Němeček, K., Kodeš, V., Žigová, A., 2012. Using dye tracer for visulization of preferential flow at macro- and microscales. Vadose Zone Journal, 11, 1-10.

Kodešová, R., Němeček, K., Žigová, A., Nikodem, A., Fér, M., 2015. Using dye tracer for visualizing roots impact on soil structure and soil porous system. Biologia, 70, 1439-1443.

Kuráž, M., Mayer, P., Pech, P., 2015. Solving the nonlinear and nonstationary Richards equation with two-level adaptive domain decomposition (dd-adaptivity). Applied Mathematics and Computation, 267, 207-222.

Kutílek, M., Nielsen, D.R., 1994. Soil Hydrology. Catena Verlag, Cremlingen - Destedt, Germany, 370 p.

Laine-Kaulio, H., Backnäs, S., Koivusalo, H., Laurén, A., 2015. Dye tracer visualization of flow patterns and pathways in glacial sandy till at a boreal forest hillslope. Geoderma, 259, 23-34.

Leibundgut, C., Maloszewski, P., Kulls, C., 2009. Tracers in Hydrology. John Wiley \& Sons, Chichester, UK, 415 p.

Lundström, U.S., van Breemen, N., Bain, D., 2000. The podzolization process. A review. Geoderma, 94, 91-107.

Marín-Castro, B.E., Geissert, D., Negrete-Yankelevich, S., Gómez-Tagle Chávez, A., 2016. Spatial distribution of 
hydraulic conductivity in soils of secondary tropical monmontane cloud forests and shade coffee agroecosystems. Geoderma, 283, 57-67.

Nash, J., Sutcliffe, J., 1970. River flow forecasting through conceptual models part $\mathrm{i}-\mathrm{a}$ discussion of principles. J. Hydrol., 10, 282-290.

Negrete-Yankelevich, S., Fox, G.A., 2015. Spatial variation and linear modeling of ecological data. In: Fox, G.A., NegreteYankelevich, S., Sosa, J.V. (Eds.): Ecological Statistics: Contemporary Theory and Application. University Press, Oxford, pp. 228-260.

Nobles, M.M., Wilding, L.P., Lin, H.S., 2010. Flow pathways of bromide and Brilliant Blue FCF tracers in caliche soils. J. Hydrol., 393, 114-122.

Pavlásek, J., Ředinová, J., Skalská, P., 2009. Evaluation of monitoring on Modrava catchments. Soil Water Res., 4 (Special Issue 2), 66-74.

Pavlásek, J., Tesař, M., Máca, P., Hanková, R., Hudečková, K., Jačka, L., Klose, Z., Ředinová, J., 2010. Ten years of hydrological monitoring in upland microcatchments in the Bohemian Forest, Czech Republic. In: Herrmann, A., Schumann, S. (Eds.): Status and Perspectives of Hydrology in Small Basins. Red Book IAHS No. 336. IAHS Press, Wallingford, pp. 213-218.

Pennock, D., Yates, C., Braidek, J., 2008. Soil sampling designs. In: Carter M.R., Gregorich, E.G. (Eds.): Soil Sampling and Methods of Analysis. 2nd ed. CRC Press Taylor \& Francis, Boca Raton, USA, pp. 1-14.

Qian, J., Wu, Y., Zhang, Y., Liu, Y., Lu, Y., Yu, Z., 2015. Evaluating differences in transport behavior of sodium chloride and Brilliant Blue FCF in sand columns. Transport in Porous Media, 109, 765-779.

Reynolds, W.D., 2008. Saturated hydraulic properties: Well permeameter. In: Carter M.R., Gregorich, E.G. (Eds.): Soil Sampling and Methods of Analysis. 2nd ed. CRC Press Taylor \& Francis, Boca Raton, USA, pp. 1025-1042.

Reynolds, W.D., Bowman, B.T., Brunke, R.R., Drury, C.F., Tan, C.S., 2000. Comparison of tension infiltrometer, pressure infiltrometer, and soil core estimates of saturated hydraulic conductivity. Soil Sci. Soc. Am. J., 64, 478-484.

Reynolds, W.D., Lewis, K.L., 2012. A drive point application of the Guelph permeameter method for coarse-textured soils. Geoderma, 187-188, 59-66.

Rezaei, M., Seuntjens, P., Shahidi, R., Joris, I., Boënne, W., AlBarri, B, Cornelis, W., 2016. The relevance of in-situ and laboratory characterization of sandy soil hydraulic properties for soil water simulations. J. Hydrol., 534, 251-265.

Sander, T., Gerke, H.H., 2007. Preferential flow patterns in paddy fields using a dye tracer. Vadose Zone J., 6, 105-115.

Sakamoto, Y., Ishiguro, M., Kitagawa G., 1986. Akaike Information Criterion Statistics. D. Reidel Publishing Company, Springer, Netherlands, 290 p.

Schwen, A., Backus, J., Yang, Y., Wendroth, O., 2014a. Characterizing land use impact on multi-tracer displacement and soil structure. J. Hydrol., 519, 1752-1768.
Schwen, A., Zimmermann, M., Bodner, G., 2014b. Vertical variations of soil hydraulic properties within two soil profiles and its relevance for soil water simulations. J. Hydrol., 516, 169-181.

Seuntjens, P., Mallants, D., Toride, N., Cornelis, C., Geuzens, P., 2001. Grid lysimeter study of steady state chloride transport in two Spodosol types using TDR and wick samplers. J. Contam. Hydrol., 51, 13-39.

Shapiro, S.S., Wilk, M.B., 1965. Analysis of variance test for normality (complete samples). Biometrika, 52, 591-611.

Shin, Y., Mohanty, B.P., Ines, A.V.M., 2012. Soil hydraulic properties in one-dimensional layered soil profile using layer-specific soil moisture assimilation scheme. Water Resour. Res., 48, W06529.

Si, B.C., M. Dyck, Parkin, G., 2011. Flow and transport in layered soils. Can. J. Soil Sci., 91, 127-132.

Swarowsky, A., Dahlgren, R.A., Tate, K.W., Hopmans, J.W., O'Geen, A.T., 2011. Catchment-scale soil water dynamics in a Mediterranean-type oak woodland. Vadose Zone J., 10, 800-815.

Šimůnek, J., van Genuchten, M.T., Šejna, M., 2016. Recent developments and applications of the HYDRUS computer software packages. Vadose Zone Journal, 15, 1-25.

Sommer, M., Halm, D., Geisinger, C., Andruschkewitsch, I., Zarei, M., Stahr, K., 2001. Lateral podzolization in a sandstone catchment. Geoderma, 103, 231-247.

van Genuchten, M.T., 1980. A closed form equation for predicting the hydraulic conductivity of unsaturated soils. Soil Sci. Soc. Am. J., 44, 892-898.

Vereecken, H., Weynants, M., Javaux, M., Pachepsky, Y., Schaap, M.G., van Genuchten, M.T., 2010. Using pedotransfer functions to estimate the van GenuchtenMualem soil hydraulic properties: a review. Vadose Zone J., 9, 795-820.

Wang, C., McKeague, J.A., 1982. Illuviated clay in sandy podzolic soils of New Brunswick. Can. J. Soil Sci., 62, 7989.

Wang, K., Zhang, R., 2011. Heterogeneous soil water flow and macropores described with combined tracers of dye and iodine. J. Hydrol., 397, 105-117.

Waroszewski, J., Egli, M., Kabała, C., Kierczak, J., Brandova, D., 2016. Mass fluxes and clay mineral formation in soils developed on slope deposits of the Kowarski Grzbiet (Karkonosze Mountains, Czech Republic/Poland). Geoderma, 264, 363-378.

Webb, T.H., Claydon, J.J., Harris, S.R., 2000. Quantifying variability of soil physical properties within soil series to address modern land-use issues on the Canterbury Plains, New Zealand. Aust. J. Soil Res., 38, 1115-1129.

Zettl, J.D., Barbour, S.L., Huang, M., Si, B.C., Leskiw, L.A., 2011. Influence of textural layering on field capacity of coarse soils. Can. J. Soil Sci., 91, 133-147.

Zhang, Z.F., Groenevelt, P.H, Parkin, G.W., 1998. The well shape factor for the measurement of soil hydraulic properties using the Guelph permeameter. Soil Till. Res., 49, 219-221. 